\title{
WATERMARK DENGAN GABUNGAN STEGANOGRAFI DAN VISIBLE WATERMARKING
}

\section{Watermark Using Steganography and Visible Watermarking}

\author{
Juni Rosmiyati, jrosmiyati@gmail.com ${ }^{1)}$, Teady Matius Surya Mulyana, \\ tmulyana@bundamulia.ac.id ${ }^{2)}$ \\ ${ }^{122)}$ Teknik Informatika / Fakultas Teknik Dan Desain, Universitas Bunda Mulia
}

\begin{abstract}
Images, that are currently circulating on the internet are many, such as advertising images for the promotion of products from a particular brand / institution, the image of the digital image, photographs of the works of famous photographers and many other examples. To identify each image appropriately, it can be added with a special logo or sign that is easily recognizable to the user. But the current advanced technology also supports duplication of the same logo / sign by irresponsible parties. Using the LSB and Grayscale methods, information such as text can be inserted into the watermark image that you want to use. Where there is a combination between the steganography process and the watermark process in one medium so that it can contain information visually and invisible. By using a stegowater application that incorporates stenographic and watermark processes, the user can use it to identify the authenticity of the image being processed, has been through the modification process or not.

Keywords: Image, Steganografi, Watermark
\end{abstract}

\begin{abstract}
ABSTRAK
Citra, gambar atau image yang saat ini beredar di internet sangatlah banyak, misal gambar iklan untuk promosi produk dari suatu brand/institusi tertentu, citra hasil karya digital image, foto pemandangan hasil karya fotografer terkenal dan masih banyak contoh lain. Untuk mengidentifikasi masing-masing citra dengan tepat, dapat ditambahkan dengan logo atau tanda khusus yang mudah dikenali oleh user. Tetapi teknologi yang maju saat ini juga mendukung dapat dilakukannya duplikasi dari logo/ tanda yang sama oleh pihak yang tidak bertanggung jawab. Dengan menggunakan metode LSB dan Grayscale, informasi seperti teks dapat disisipkan ke dalam citra watermark yang ingin digunakan. Dimana terjadi penggabungan antara proses steganografi dan proses watermark dalam satu media sehingga dapat berisi informasi secara visible dan invisible. Dengan menggunakan aplikasi stegowater yang menggabungkan proses steganografi dan watermark, user dapat menggunakannya untuk mengidentifikasi keaslian dari citra yang diproses, telah melalui proses modifikasi atau tidak.
\end{abstract}

Kata Kunci: Citra, Steganographi, Watermark

\section{PENDAHULUAN}

Istilah stegowater berasal dari dua kata yang digabungkan, yaitu steganografi dan watermark.

Dimana kata "steganografi" berasal dari bahasa Yunani steganos, yang artinya "tersembunyi atau terselubung", dan graphein, "menulis". Sehingga steganografi adalah seni dan ilmu menulis pesan tersembunyi atau menyembunyikan pesan dengan suatu cara. Steganografi membutuhkan dua properti, yaitu wadah penampung dan data rahasia yang akan disembunyikan. Steganografi digital merupakan media digital sebagai wadah penampung, misalnya citra, audio, teks, dan video. Data rahasia yang disembunyikan juga dapat berupa citra, audio, teks atau video.

Sedangkan untuk watermark, Guo (Guo, 2009) menjelaskan 2 jenis watermark, yaitu visible watermarking dan invisible watermarking. Braudaway (Braudaway, 1996), Men (Meng, 1998), Kankanhalli (Kankanhalli, 1999) dan Chen (Chen, 2000) seperti yang dikutip oleh Guo 
(Guo, 2009) menjelaskan bahwa visible watermarking merupakan suatu proses pembentukan citra terwatermark dimana citra watermark ditampilkan pada citra terwatermark secara kasat mata. Teknik watermarking bekerja dengan menyisipkan sedikit informasi yang menunjukkan kepemilikan, tujuan, atau data lain pada media digital tanpa mempengaruhi kualitasnya.

\section{METODE PENELITIAN}

digunakan metode tertentu untuk mendukung proses yang berjalan, seperti dalam steganografi menggunakan metode LSB dan proses watermark menggunakan metode grayscale dan LSB.

Least Significant Bit (LSB) adalah algoritma yang dalam prosesnya membaca bit dari sumber tertentu sehingga dapat dilakukan perubahan nilai bit terbelakang sesuai dengan bit yang diinginkan. Dalam proses stegowater, metode LSB dilibatkan pada proses steganografi, pembuatan header, dan setelah proses watermark.

Tahapan dalam implementasi LSB terbagi menjadi 3 yaitu:

Tahap Pertama: Memperoleh nilai bit, baik dari sisi citra maupun dari stegoteks yang akan digunakan sebagai nilai bit terbelakang. Citra memperoleh nilai bitnya dari intensitas citra, sedangkan stego-teks dapat memanfaatkan kode ASCII dalam konversi huruf ke nilai biner atau sebaliknya.

Tahap Kedua: Nilai desimal yang diperoleh diolah Untuk mendapatkan nilai bit terkecil dapat memanfaatkan persamaan (1).

$\mathrm{k}=\mathrm{B}_{\mathrm{st}} \bmod 2$

dimana:

$\mathrm{k} \quad$ : Nilai bit terkecil dari Bst

$\mathrm{B}_{\mathrm{st}} \quad$ : Biner dari citra/stego-teks

Tahap Ketiga: Memasukkan nilai bit ke dalam nilai bit citra.

Jika $\operatorname{Bc}(\mathrm{x}, \mathrm{y})$ di mod dengan 2 dan bernilai $\mathrm{k}$, maka tidak terjadi perubahan nilai pada $\mathrm{Bc}(\mathrm{x}, \mathrm{y})$. Tetapi jika tidak, maka akan diuji nilai $\mathrm{k}$. Apabila $\mathrm{k}$ bernilai 0 , maka dilanjutkan ke persamaan (2), sedangkan jika $\mathrm{k}$ bernilai 1, maka dilanjutkan ke persamaan (3).

$\mathrm{Bc}^{\prime}(\mathrm{x}, \mathrm{y})=\mathrm{Bc}(\mathrm{x}, \mathrm{y})-1$

$B c^{\prime}(x, y)=B c(x, y)+1$

dimana:

$\mathrm{Bc}(\mathrm{x}, \mathrm{y})$ : Nilai bit citra

$\mathrm{Bc}^{\prime}(\mathrm{x}, \mathrm{y})$ : Nilai bit citra setelah di proses

$\mathrm{k} \quad$ : Nilai bit terkecil dari Bst

Mulyana (Mulyana, 2013) menjelaskan bahwa, jika suatu citra watermark dijadikan citra grayscale, yang hanya mempunyai satu nilai intensitas, maka jika nilai intensitas pada piksel-piksel dari citra watermark yang telah diubah menjadi citra grayscale tersebut digunakan untuk menaikkan atau menurunkan nilai intensitas channel RGB suatu citra dengan posisi dan variasi intensitas masing-masing piksel yang sama dengan citra watermark akan menghasilkan variasi gelap dan terang pada piksel-piksel citra yang akan diberi watermark dengan posisi-posisi yang sama dengan posisi pada citra watermark. Di dalam proses stegowater, metode Grayscale hanya dilibatkan dalam proses watermarking saja.

Menurut Mulyana (Mulyana, 2013), proses watermarking dengan metode grayscale melalui lima tahapan, yaitu:

Tahap Pertama: Preprocessing, penyiapan citra watermark, dimana citra watermark akan diproses pengubahan menjadi abu yang dapat dilakukan dengan berbagai cara, salah satunya dapat dilakukan dengan metode sederhana seperti dikutip oleh Simarmata (Simarmata, 2007) dan Sutoyo (Sutoyo,2009), dapat dilihat pada persamaan (4).

$f(x, y)=(R(x, y)+G(x, y)+B(x, y)) / 3$

dimana:

$f(\mathrm{x}, \mathrm{y})$ : pixel abu-abu

$R(\mathrm{x}, \mathrm{y})$ : intensitas channel Red

$\mathrm{G}(\mathrm{x}, \mathrm{y})$ : intensitas channel Green 
$\mathrm{B}(\mathrm{x}, \mathrm{y})$ : intensitas channel blue

Tahap Kedua: Bitmaping, pemindahan citra watermark yang sudah menjadi citra abu-abu akan dipindahkan ke bitmap, bersamaan dengan proses ini piksel yang dianggap latar belakang diset dengan nilai 0 , sedangkan piksel latar depan akan diset nilai apa adanya. Pada tahap ini, ditentukan nilai intensitas terkecil dari latar depan citra.

Tahap Ketiga: Pembuatan bitmap penapis, penggantian nilai piksel latar depan citra watermark pada bitmap dengan nilai patokan yang didapat dari nilai terendah intensitas citra watermark (atau dengan nilai lainnya) dengan konstanta. Proses hanya dilakukan pada piksel yang nilai intensitasnya bukan 0 , atau piksel latar belakang. Nilai pengganti didapat dengan persamaan (5).

$\mathrm{G}^{\prime}(\mathrm{x}, \mathrm{y})=\min (\mathrm{G}(\mathrm{x}, \mathrm{y}))+\mathrm{G}(\mathrm{x}, \mathrm{y})+\mathrm{K}$

dimana:

$\mathrm{G}^{\prime}(\mathrm{x}, \mathrm{y})$ : Bitmap Citra Watermark

$\mathrm{G}(\mathrm{x}, \mathrm{y})$ : Citra Watermark

$\mathrm{K}$ : Konstanta

Tahap Keempat: Operasi penjumlahan pada citra utama dengan nilai pada bitmap watermark. Pada operasi ini setiap piksel pada bitmap penapis sudah mengandung suatu nilai penapis, karena itu operasi penjumlahan cukup dengan menjumlah piksel-piksel pada citra utama dengan piksel-piksel pada bitmap citra watermark tanpa mengalikan dengan nilai penapisnya. Persamaan penjumlahan itu dapat dilakukan dengan persamaan (6).

$\mathrm{F}(\mathrm{x}, \mathrm{y})=\mathrm{C}(\mathrm{x}, \mathrm{y})+\mathrm{G}^{\prime}(\mathrm{x}, \mathrm{y})$

dimana:

$F(\mathrm{x}, \mathrm{y})$ : Citra hasil watermarking

$C(\mathrm{x}, \mathrm{y})$ : Citra utama

G'(x,y) : Bitmap Citra Watermark

Tahap Kelima: Setelah nilai pada $\mathrm{F}(\mathrm{x}, \mathrm{y})$ berubah sesuai tahapan yang sudah ditetapkan, nilai bit terakhir dari $\mathrm{F}(\mathrm{x}, \mathrm{y})$ harus dikembalikan dalam bentuk yang sama dengan menggunakan persamaan (7).
Setelah proses watermark selesai, dilakukan proses untuk menghitung jumlah karakter stego-teks maksimal yang dapat diinput ke dalam citra watermark dengan menggunakan persamaan (7) berikut.

$\mathrm{J}_{\text {char }}=\left(\left(\mathrm{W}_{\text {width }}-\mathrm{S}_{\mathrm{x}}\right) \operatorname{div} 8\right) *\left(\left(\mathrm{~W}_{\text {height }}-\mathrm{S}_{\mathrm{y}}\right)\right.$ $\operatorname{div} 8) * 8-2$

dimana:

watermark

$\mathrm{S}_{\mathrm{x}} \quad$ : Posisi $\mathrm{x}$ dari stego-teks

$\mathrm{S}_{\mathrm{y}} \quad$ : Posisi y dari stego-teks

$\mathrm{W}_{\text {width }}$ : Lebar dari citra

watermark

$\mathrm{W}_{\text {height }}$ : Tinggi dari citra

$\mathrm{J}_{\text {char }} \quad$ : Jumlah stego-teks

Header merupakan bagian informasi data yang disimpan ke dalam citra yang dituju, dengan tujuan untuk mempermudah proses Read.

Berdasarkan tempat penyimpanan, header terbagi menjadi 2, yaitu:

1. Header $\mathrm{S}$, yang terletak di dalam citra watermark, berisi informasi tentang letak dari stego-teks dan besar ukuran stego-teks. Contoh : |10,10;181;15|

2. Header $\mathrm{W}$, yang terletak di citra dasar, berisi informasi dari letak citra watermark, arah penyimpanan dan besar ukuran citra watermark. Contoh : |10,10;181h;15|

Berdasarkan arah penyimpanan, header juga terbagi dalam 2, yaitu:

1. Horizontal (h), dimana data disimpan secara horizontal (kiri ke kanan), yang terpengaruh oleh posisi $\mathrm{x}$ yang dismasukkan dan lebar (width) dari citra. Contoh : |10,10;181h;15|

2. Vertikal (v), dimana data tersimpan secara vertikal (atas ke bawah), yang terpengaruh oleh posisi y yang dimasukkan dan tinggi (height) dari citra. Contoh : |10,10;180v;15|

Dalam pembuatan header $\mathrm{S}$, tahapan yang dilalui terdiri dari 4 tahap, yaitu:

Tahap Pertama: Membuat header sesuai dengan format yang sudah ditentukan, dimana height dan weight 
menentukan persamaan yang digunakan. Width menggunakan persamaan (8) dan (9), sedangkan height menggunakan persamaan (10) dan (11).

$\mathrm{H}_{\mathrm{s}}=\mathrm{IW}_{\mathrm{x}}+\mathrm{S}_{\mathrm{x}}, \mathrm{W}_{\mathrm{y}}+\mathrm{S}_{\mathrm{y}} ; \mathrm{W}_{\mathrm{x}}+\mathrm{W}_{\text {width }} ; \mathrm{W}_{\mathrm{y}}+$

$\mathrm{Y}_{\max } \mathrm{l}$

$\mathrm{Y}_{\max }=\left(\left(\mathrm{W}_{\text {height }}-\mathrm{S}_{\mathrm{y}}\right) \operatorname{div} 8\right) * 8+\mathrm{S}_{\mathrm{y}}$

$\mathrm{H}_{\mathrm{s}}=\mathrm{IW}_{\mathrm{x}}+\mathrm{S}_{\mathrm{x}}, \mathrm{W}_{\mathrm{y}}+\mathrm{S}_{\mathrm{y}} ; \mathrm{W}_{\mathrm{y}}+\mathrm{W}_{\text {height }} ; \mathrm{W}_{\mathrm{x}}+$

$\mathrm{X}_{\max } \mid$

$\mathrm{X}_{\max }=\left(\left(\mathrm{W}_{\text {width }}-\mathrm{S}_{\mathrm{x}}\right) \operatorname{div} 8\right) * 8+\mathrm{S}_{\mathrm{x}}$

dimana:

$\mathrm{S}_{\mathrm{x}} \quad$ : Posisi $\mathrm{x}$ dari stego-teks

$\mathrm{S}_{\mathrm{y}} \quad$ : Posisi y dari stego-teks

$\mathrm{W}_{\mathrm{x}}$ : Posisi $\mathrm{x}$ dari watermark

$\mathrm{W}_{\mathrm{y}}$ : Posisi y dari watermark

$\mathrm{X}_{\max }$ : Batas $\mathrm{X}$ dari citra watermark

$\mathrm{Y}_{\max }$ : Batas Y dari citra watermark

$\mathrm{W}_{\text {width }}$ : Lebar citra watermark

$\mathrm{W}_{\text {height }}$ : Tinggi citra watermark

Tahap Kedua: Mengkonversi nilai string dari header ke dalam kode ASCII. Contoh : $|10,10 ; 181 ; 15|=12949484449$ 4859495649594953124

Tahap Ketiga: Mengkonversi kode ASCII dari header ke dalam bentuk biner.

$\begin{array}{ll}124 & : 01111100 \\ 49 & : 00110001 \\ 48 & : 00110000 \\ 44 & : 00101100 \\ 59 & : 00111011 \\ 56 & : 00111000 \\ 53 & : 00110101\end{array}$

Tahap Keempat: Memasukkan bilangan biner yang diperoleh ke dalam citra watermark dengan menggunakan metode LSB.

Sedangkan dalam pembuatan header $\mathrm{W}$, tahapan yang dilalui terdiri dari 4 tahap, yaitu:

Tahap Pertama: Membuat header sesuai dengan format yang sudah ditentukan, dimana height dan weight menentukan persamaan yang digunakan. Width menggunakan persamaan (12), sedangkan height menggunakan persamaan (13).
$\mathrm{H}_{\mathrm{w}}=\mid \mathrm{W}_{\mathrm{x}}, \mathrm{W}_{\mathrm{y}} ; \mathrm{W}_{\mathrm{x}}+\mathrm{W}_{\text {width }}+\operatorname{dir} ; \mathrm{W}_{\mathrm{y}}+4 \mathrm{I}$.

$\mathrm{H}_{\mathrm{w}}=\left|\mathrm{W}_{\mathrm{x}}, \mathrm{W}_{\mathrm{y}} ; \mathrm{W}_{\mathrm{x}}+\mathrm{W}_{\text {height }}+\operatorname{dir} ; \mathrm{W}_{\mathrm{x}}+4\right| \ldots$

dimana:

$\mathrm{W}_{\mathrm{x}}$ : Posisi $\mathrm{x}$ dari watermark

$\mathrm{W}_{\mathrm{y}}$ : Posisi y dari watermark

$\mathrm{W}_{\text {width }}$ : Lebar citra watermark

$\mathrm{W}_{\text {height }}$ : Tinggi citra watermark

dir : Arah penyimpanan header

Tahap Kedua: Mengkonversi nilai string dari header ke dalam kode ASCII. Contoh : |10,10;181h; $15 \mid=12949484449$ 4859495649104594953124

Tahap Ketiga: Mengkonversi kode ASCII dari header ke dalam bentuk biner.

$\begin{array}{ll}124 & : 01111100 \\ 49 & : 00110001 \\ 48 & : 00110000 \\ 44 & : 00101100 \\ 59 & : 00111011 \\ 56 & : 00111000 \\ 104 & : 01101000 \\ 53 & : 00110101\end{array}$

Tahap Keempat: Memasukkan bilangan biner yang diperoleh ke dalam citra dasar dengan menggunakan metode LSB.

Metode LSB digunakan juga dalam proses Read, untuk membaca nilai bit yang tersimpan melalui lima tahapan, yaitu:

Tahap Pertama: Nilai piksel yang diperoleh dari citra stegowater diubah ke dalam bentuk biner.

$254: 11111110$
$255: 11111111$

Tahap Kedua: Nilai biner yang diperoleh, dibaca hanya bit terakhirnya saja menggunakan persamaan (1).

$11110000: 0$
$11111111: 1$

Tahap Ketiga: Bit disusun secara beruturan sesuai dengan letaknya, lalu dibagi per 8 bit seperti yang ditunjukkan dalam Gambar 1. 


\begin{tabular}{|l|l|l|l|l|l|l|l|}
\hline 0 & 1 & 1 & 1 & 1 & 1 & 0 & 0 \\
\hline 0 & 1 & 1 & 0 & 1 & 0 & 1 & 0 \\
\hline 0 & 1 & 1 & 1 & 0 & 1 & 0 & 1 \\
\hline 0 & 1 & 1 & 0 & 1 & 1 & 1 & 0 \\
\hline 0 & 1 & 1 & 0 & 1 & 0 & 0 & 1 \\
\hline 0 & 0 & 1 & 0 & 1 & 1 & 1 & 0 \\
\hline 0 & 1 & 1 & 1 & 0 & 1 & 1 & 0 \\
\hline 0 & 1 & 1 & 1 & 1 & 0 & 0 & 0 \\
\hline
\end{tabular}

Gambar 1. Bit Terakhir yang Disusun

Tahap Ketiga: Dilakukan konversi nilai biner yang didapat, tiap 8 bit biner ke dalam bilangan desimal.

$\begin{array}{ll}01111100 & : 124 \\ 01101010 & : 106 \\ 01110101 & : 117 \\ 01101110 & : 110 \\ 01101001 & : 105 \\ 00101110 & : 46 \\ 01110010 & : 114 \\ 01111100 & : 124\end{array}$

Tahap Kelima: Bilangan desimal yang diperoleh, diubah ke dalam kode ASCII.

12410611711010546114124 : ljuni.r|

\section{HASIL DAN PEMBAHASAN}

Keuntungan yang diperoleh dengan menggunakan metode LSB antara lain:

1. Perubahan yang terjadi tidak mudah dideteksi secara kasat mata.

2. Mutu dari citra penampung tidak jauh berubah dibanding aslinya.

3. Ukuran dari data yang bisa disimpan tergantung dari ukuran citra penampung, dimana makin besar ukuran citra penampung, makin banyak data (untuk sementara berupa teks) yang bisa disimpan di dalamnya.

Sedangkan kekurangan dari metode LSB adalah tidak tahan terhadap manipulasi citra seperti crop, rotate, hue, saturation, dan lain-lain yang dapat mengakibatkan berubahnya nilai bit ataupun posisi datanya. Dimana kekurangan ini dapat digunakan untuk mengetahui apakah citra tersebut telah mengalami proses modifikasi atau tidak.

metode $\begin{gathered}\text { Keuntungan dari penggunaan } \\ \text { Grayscale adalah dapat }\end{gathered}$ mempermudah proses watermark sehingga menjadi lebih cepat dibandingkan dengan menggunakan ketiga channel warna sekaligus (RGB).

Sedangkan kelemahannya pada metode Grayscale, yaitu:

1. Apabila nilai dari latarnya atau citra dasar (base) mencapai 255, maka tidak dapat terjadi proses watermarking ke dalam citra tersebut. Sehingga diperlukan suatu metode yang dapat digunakan untuk mengatur tinggi rendahnya nilai tunggal Grayscale.

2. Jika terjadi thresholding, maka watermark pada piksel yang di threshold tersebut tidak terlihat jelas.

Percobaan berikut diuji pada software Stegowater v1.4.02.

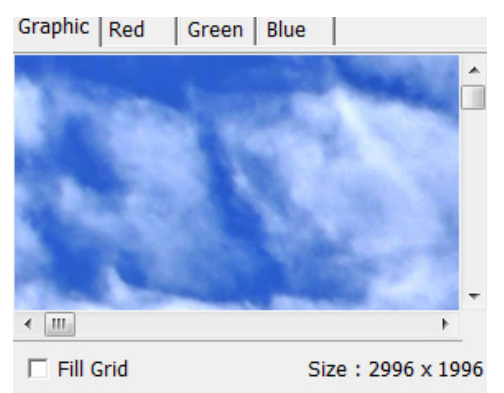

Gambar 2. Citra dasar (base)

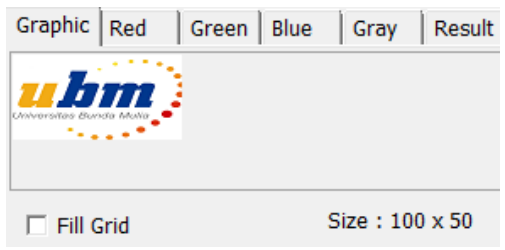

\section{Gambar 3. Citra watermark}

Proses dalam stegowater terbagi menjadi 2, yaitu read (membaca) dan write (menulis). Proses write terbagi menjadi empat bagian, yaitu:

1. Input citra dasar (base)

2. Input citra watermark 
3. Input nilai posisi steganografi, watermark dan stego-teks

4. Output hasil citra stegowater

Citra pada Gambar 3 di-watermark ke dalam Gambar 2, lalu diatur nilai posisi watermark dan steganograf, serta isi dari stego-teks seperti pada Gambar 4. Hasil akhir dari proses adalah citra stegowater seperti yang ditunjukkan dalam Gambar 5.

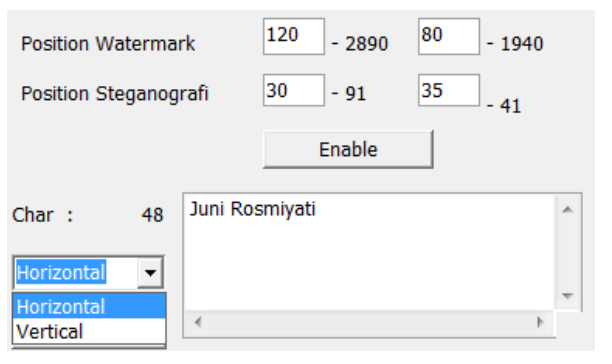

Gambar 4. Nilai posisi watermark, steganografi dan isi stego-teks.

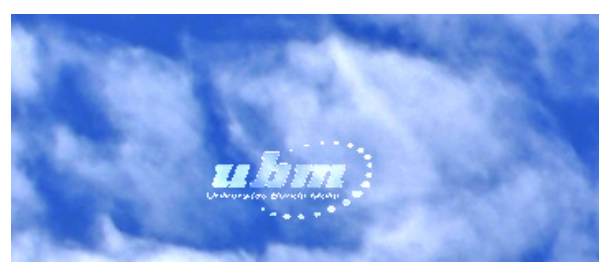

Gambar 5. Citra stegowater yang berisikan citra base, citra watermark dan stego-teks di dalamnya.

Citra stegowater seperti pada Gambar 5, yang diperoleh dari proses write memiliki data stego-teks didalamnya. Dimana isi stego-teks tersebut dapat dibaca kembali dengan menggunakan proses Read dalam aplikasi stegowater. Proses Read terbagi menjadi 2 tahap, yaitu:

1. Input citra stegowater

2. Input dan output proses ekstrak

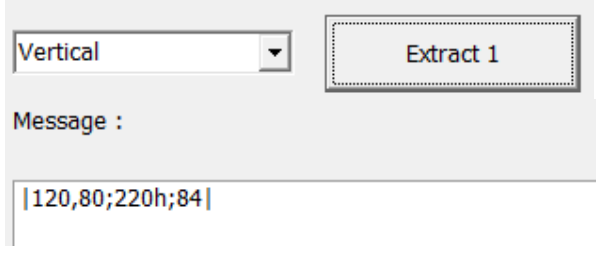

Gambar 6. Proses Ekstrak 1

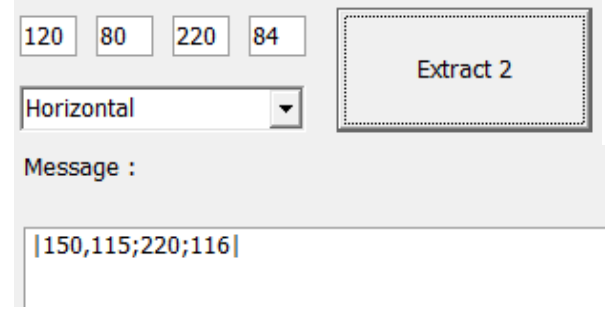

Gambar 7. Proses Ekstrak 2

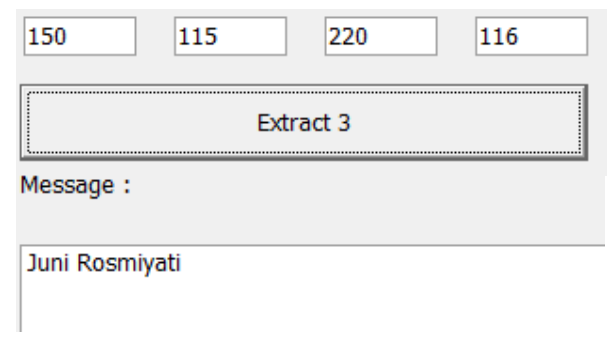

\section{Gambar 8. Proses Ekstrak 3}

Setelah citra stegowater dipilih oleh user, proses pada Gambar 7 dan selanjutnya dapat dilanjutkan. Gambar 7 menunjukkan kode header untuk watermark, sedangkan pada Gambar 6 menunjukkan kode header untuk steganografi. Dan pada Gambar 8, menunjukkan lokasi dari stego-teks dan isi stego-teks.

Dilakukan uji proses modifikasi pada citra stegowater yang dihasilkan, seperti pengubahan brightness, contrast, crop, rotasi, flip, saturasi, hue, luminesce dan zoom untuk melihat apakah stego-teks dan header masih lengkap setelah mengalami proses modifikasi. Hasil ujicoba dapat dilihat pada Tabel 1.

dimana:

+ : Header dari ekstrak benar

! : Terdapat bagian yang benar tetapi tidak sempurna

- : Hasil muncul tapi salah semua

o : Hasil tidak muncul sama sekali

Pada citra stegowater yang dilakukan perubahan brightness sebesar +45 dari awalnya, hasil yang diperoleh pada, Ekstrak 1 tetap menghasilkan header yang semestinya, tetapi pada ekstrak 2, header yang muncul terdapat bagian benar 
tetapi tidak sempurna, dan terakhir pada ekstrak 3, isi stego-teks tidak muncul sama sekali.

Tabel 1. Hasil Uji Perlakuan

\begin{tabular}{|r|l|c|c|c|}
\hline No & Perlakuan & Ekstrak & Ekstrak & Ekstrak \\
\hline 1 & Brightness +45 & + & $!$ & 0 \\
2 & Brightness +59 & 0 & - & - \\
3 & contrast +30 & o & o & o \\
4 & crop & 0 & 0 & o \\
5 & Flip Horisontal & o & o & o \\
6 & Flip Vertikal & o & o & o \\
7 & Luminescen +50 & o & o & o \\
8 & Luminescen -80 & o & o & o \\
9 & Rotasi 180 & o & o & o \\
10 & Zoom & o & o & o \\
11 & Saturation -100 & + & + & + \\
12 & Saturation -67 & + & + & + \\
13 & hue +50 & + & + & + \\
14 & hue -50 & + & + & + \\
15 & hue -100 & + & + & + \\
\hline
\end{tabular}

Perubahan brightness sebesar +59 menghasilkan nilai ekstrak 1 , header $\mathrm{W}$ dari percobaan 8 masih benar. Dan hasil yang diperoleh, ekstrak 1 ternyata tidak menghasilkan header, dan perbedaan juga terdapat pada ekstrak 2 dan ekstrak 3 yang memunculkan hasil, tetapi salah semua.

Pada beberapa perlakuan berikut ini:

- Pengubahan contrast sebesar +30 .

- Pemotongan ukuran citra / crop hingga berukuran 1560x1100px.

- Pembalikkan citra/ flip secara horizontal.

- Pembalikkan citra/ flip secara vertikal.

- Luminesce citra stegowater sebesar +50 .

- Luminesce citra stegowater sebesar -80.

- Rotasi pada citra stegowater dengan rotasi sebesar 180 derajat, clockwise.

- Perbesaran pada citra stegowater hingga mencapai ukuran 1600x1200px.

Hasil ekstrak 1, 2 dan 3 dari percobaan nomor 3 sampai 10 tidak menghasilkan apapun. Sehingga modifikasi tersebut adalah jenis modifikasi yang dapat merusak nilai header dan stego-teks yang tersimpan dalam citra stegowater.

Pada percobaan nomor 11 sampai 15 citra stegowater dilakukan
- perubahan saturasi citra stegowater sebesar - 100 .

- Perubahan saturasi citra stegowater sebesar -67 .

- Perubahan nilai hue dari citra stegowater sebesar +50 .

- Perubahan nilai hue dari citra stegowater sebesar -50 .

- Perubahan nilai hue sebesar -100 pada citra stegowater.

Hasil percobaan tersebut memberikan hasil positif pada ketiga jenis ekstrak, dimana ekstrak 1 berhasil membaca header $\mathrm{W}$, ekstrak 2 berhasil membaca header $\mathrm{S}$ dan ekstrak 3 dapat mengetahui isi dari stego-teks secara sempurna. Sehingga jenis perlakuan pada percobaan 11 sampai 15 adalah jenis perlakuan yang tidak merusak nilai header dan stego-teks yang tersimpan dalam citra stegowater, meskipun perubahan warna pada citra stegowater lebih signifikan dibanding proses modifikasi lainnya.

\section{SIMPULAN}

Berdasarkan hasil uji modifikasi pada citra, proses modifikasi seperti brightness, contrast, rotate, dan zoom dapat merusak header dan stego-teks yang tersimpan di dalam citra stegowater. Sedangkan proses modifikasi seperti hue dan saturation tidak menyebabkan hilangnya stego-teks ataupun header di dalam citra stegowater.

\section{Saran}

1. Berdasarkan hasil pengujian yang diperoleh, penggunaan stego-teks di dalam citra dapat diaplikasikan pada logo sertifikasi digital sehingga dapat digunakan untuk mengetahui valid tidaknya suatu sertifikasi secara digital.

2. Dapat menambahkan unsur kriptografi unuk meningkatkan keamanan dari aplikasi seperti Caesar Cipher dalam konversi kode ASCII ke dalam biner 
atau sebaliknya sehingga lebih secure dalam melindungi data yang ada serta sekaligus melengkapi sebuah citra dengan 3 jenis proteksi media digital.

\section{DAFTAR PUSTAKA}

[1] Guo. Jing-Ming \& Chang. ChiaoHao, (2009). Prediction-Based Watermarking Schemes for DCTBased Image Coding, 2009 Fifth International Conference on Information Assurance and Security, IEEE, (P619-622).

[2] Mulyana. Teady M. S., (2013), Penggunaan Nilai Skala Keabuan
Dari Citra Watermark Sebagai Cetak Biru Dari Visible Watermarking, Seminar Nasional Informatika 2013 Proceddings Buku 2, UPN "Veteran" Yogyakarta, Yogyakarta , pp 23.

[3] Simarmata. J., Chandra. T., (2007), Grafika Komputer, Penerbit Andi, Yogyakarta.

[4] Sutoyo, T. Mulyanto, E. Suhartono, V. Nurhayati, OD. Wijanarto., (2009), Teori Pengolahan Citra Digital, Penerbit Andi, Yogyakarta. 